\title{
Effect of some saprotrophic soil fungi on the embryonic development of Ascaris summ (Nematoda)
}

\author{
WANDA KUZNA-GRYGIEL ${ }^{1}$, LIDLA KOLODZIEJCZYK ${ }^{2}$, KRYSTYNA JANOWICZ ${ }^{2}$, \\ and KINGA MAZURKIEWICZ-ZAPALOWICZ ${ }^{2}$
}

${ }^{t}$ Chair of Biology and Medical Parasitology, Pomeranian Academy of Medicine in Szcrecin Powstańców Wielkopolskich 72, PL-71-110 Szczecin, Poland

e-mail: kuzgryg@sci.pam.szezecin.pl

${ }^{2}$ Chair of Applied Entomology, Agricultural Academy in Szczecin

Slowackiego 17. PL-71.434 Szczecin, Poland

${ }^{3}$ Chair of Zoology, Agricultural Academy in Szezecin

Judyma 20, PL-71-466 Szczecin, Poland

Kuźna-Grygicl W, Kołodziejczyk L, Janowicz K, Mazurkiewicz-Zapałowicz K: Effect of some saprotrophic soil fungt an the embryonic development of Ascar is summ. Acta Mycol. 36 (2) $283-291,2001$.

Eflect of Penicillium frequentans and Stachybotrys chartarum fung on the embryonic development of Ascaris swum were studied in the present paper. In eggs that were incubated with fungi, significant delay of initiation of zygote division, as well as retardation of the development of individual stages of embryogenesis, was given a closer insight. Additionally, the following phenomena were obsarved: vacuolisation of zygote and disturbances in the distribution of yolk. aon-syachronous and unequal divisions of blastomere, deformations of the blastula, gastrula, and larval stages. The above changes were more distinct in egg that were incubated with $P$. frequentans. In the cultures with $P$. frequentans, a significantly lower number of larvae, as well as their earlier mortality were observed.

Key words: soil fungi, embryogenesis, Ascaris sutum.

\section{INTRODUCTION}

Soil plays an important role in the epidemiology of soil-born parasitic diseases, both human and animal as well. Species of the genus Ascaris: A. lumbricoides (parasite of human) and $A$. sum (parasite of swine) are nematodes of which embryonic development until the stage of the infective larva proceeds in the soil. Eggs of these nematodes are introduced to the soil with the cesspool or manure. They retain their infective properties for as many as 15 ycars (Krasnonos 1978). 
A. suum constitutes a problems predominately in veterinary parasitology, although humans can also become accidental hosts. In the latter case, however, the parasite reaches only the stage of larva migrans.

Research on limiting the number of infective eggs of geohelminths in the soil by the inhibition of their embryonic development has been carried out for many years. Effect of numerous physical and chemical factors on the development and viability of Ascaris sp. eggs has been relatively well investigated (G r z y b and S z y d to w sk a 1964; M i z gaj s k a 1993; $\mathrm{S} z$ k u d I i ń s k j 1998). Chemical substances, however, like pesticides, destroy the other elements of the soil biocenosis sooner than they can destroy the eggs of geohelminths (L y s e k 1979).

As early as in the 1960 s efforts were made to use soil organisms in the biological control of geohelminths. The most significant role in limiting the number of nematode eggs, among others also Ascaris, has been attributed to saprotrophic fungi that are common in the ecosystem (L y s e k 1967; Jar n i cka-Stan i os and W a w r z kie wi cz 1974; L y se k 1979; M i z g a j s k a 1994). The studies carried out by L y s c k $(1963,1967,1979$, 1982), and also by Jarnicka-Stanios and Wa wr kicwicz (1974) showed different degrees of destructive effect of ovicidal fungi on eggs of geohelminths.

A study on the effect of saprotrophic soil fungi and their metabolites on Globodera rostochiensis, a nematode parasitic on crops showed that Penicillium frequentars and Stachybotrys chartarum significantly diminished the viability of larvac of the above nematode ( $\mathrm{Mazurkiewicz-Z}$ a palowic $z$ et al. 1999).

The aim of the present study was to determine the effect of $P$. frequentans and $S$. chartarum on the course and pace of the embryonic development of Ascaris suum.

\section{MATERIALS AND METHODS}

Adult females of Ascaris suum were collected from the Municipal Slaughterhousc at Szczecin. Fertilised eggs were dissected from the terminal portion of the nematode uterus.

Saprotrophic fungi - Penicillium frequentans and Stachybotrys chartarum - were isolated from the soil and cultured on the standard PDA-Difco medium, at $25^{\circ} \mathrm{C}$.

A. suum eggs were embryonated in four cultures in Petri dishes, in physiological solution $\left(0.9 \% \mathrm{NaCl}\right.$ ), at $26^{\circ} \mathrm{C}$. One of them without fungi (served as control), and the three experimental ones with fragments of mycelium (ca $130 \mathrm{~mm}$ ) from 21-day-old cultures. Mycelium of Penicillium frequentans was placed in the experimental culture I, mycelium of Stachybotrys chartarum was placed in experimental culture II, and mycelia of both fungi species were placed in culture III. The surface area of each mycelium amounted to $65 \mathrm{~mm}^{2}$. 
The cultures were grown at a constant humidity and the constant temperature of $26^{\circ} \mathrm{C}$

The embryonic development of eggs from control- and experimental cultures were monitored daily, throughout 70 days of the experiment, in the evaluation of the ovicidal or ovistatic effect of the fungi studied: changes in the distribution of yolk, vacuolisation and granulation of cells of embryo, morphological disorders in the structures of zygote, blastomeres, morula, blastula, gastrula, and larvae, damages to the cgg shells, mycelium penetration into the eggs.

\section{RESULTS}

The duration of cleavage, gastrulation and organogenesis of Ascaris suum, in control and experimental cggs is described in Table 1.

In all experimental cultures development of the majority of eggs was delayed in comparison to the control, at the stage of zygote. In eggs incubated with $P$. frequentans, this stage was observed up to 25 th day. In three experimental cultures, the period of cleavage (from 2 blastomeres up to blastula) was significantly prolonged. In eggs incubated with $\boldsymbol{P}$. frequentans embryos, with 2 and with 4 blastomeres were observed as late as on day 25 of the culture. From day 26 on, the pace of divisions intensified. The majority of eggs in the eleavage phase (ca $60 \%$ ), mostly the morula and blastula stages, were observed within the period of 29-31 days.

Also in the culture with $S$. chartarum, the first divisions of zygote were delayed, although not as much as in culture I. Up to day 12, only 2-blastomere embryos werc observed, while later on - within 17-19 days of the experiment as many as $80 \%$ of eggs were at the stage of morula or blastula. Similar results were obtained during observation of the cleavage process in eggs that were incubated with both species of fungi at the same time. Cleavage in eggs of control group was completed not later than day 11 , whereas zygote divisions in cultures with fungi in $10 \%$ of eggs were observed as latc as on day 50 .

In control eggs, all individual developmental stages were normal (Figs $1-4)$. Abnormalities were observed at the cleavage stage of eggs incubated with fungi, most of them - in the yolk distribution and in the size of blastomeres.

In the majority of zygotes, the polar and equatorial yolk aggregation and vacuolisation of the protoplast (Fig. 5) were initially observed, however, distribution of the yolk in most eggs came to normal before the division. In initial cleavage divisions, also multinuclear blastomeres were observed (Fig. 6). Some of embryons (from 2 blastomeres to morula) consisted of blastomeres of different size (Fig. 7). Most of eggs with this kind of morphological disorders were found in the culture with $P$. frequentans (ca $30 \%$ ), and ca $10 \%-$ in the other experimental cultures. 
T a b l c 1

Effect of Penicillium frequentans and Stachybotrys chartarum on embryonic development of Ascaris sum

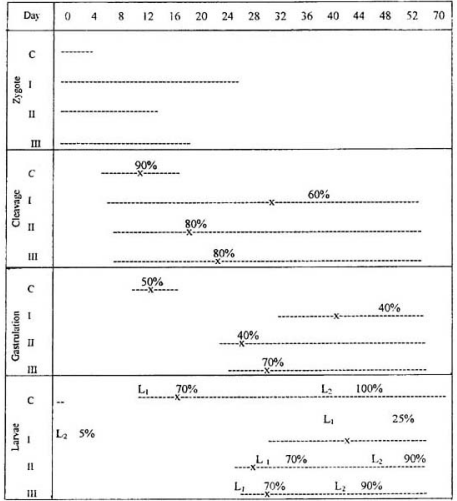

Explanations $\mathrm{x}$ - highest percentage of Ascaris suton eggs in a given developmental stage; C - control culture of Ascaris stum eggs; I - experimental culture of Ascarls stum eggs with Penicillium frequentans; II - experimental culture of Ascaris stam eggs with Stachybotrys charterum, III - experimental culture of Ascaris snum eggs with Penicillium frequentans and Stachybotrys chariarum 

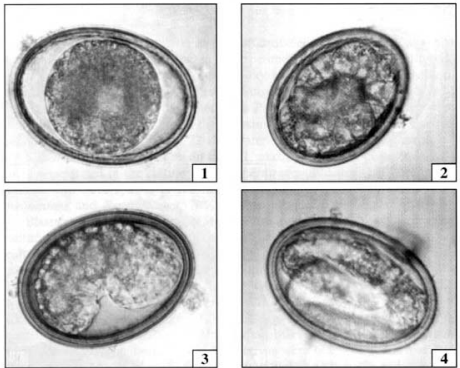

\section{PLATE I}

Fig 1. Egg of Asearis stum at the zygote stage from control culture, $\times 1000$ Fig. 2. Egg of Asceris swum at the blastula stage from control culture. $\times 1000$ Fig. 3. Egg of Asceris sum at the gastrula stage from control culture, $\times 1000$ Fig. 4. Egg of Ascorts sum containing $\mathrm{L}_{2}$ larva from control culture. $\times 1000$ 

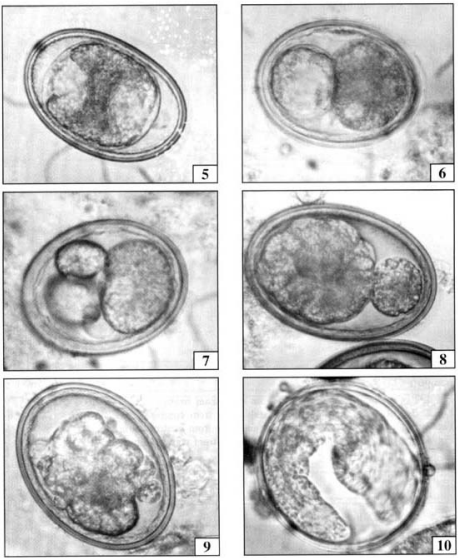

\section{PLATE II}

Fig. 5. Aggregation of yolk and vacuolisation of the zygote in Ascaris stum egg incubated with Penicillitum frequenians. $\times 1000$

Fig 6. Blastomere with a big vacuole and multinuclear blastomerc in Ascaris swum egg incubated with Pendcillium frequentans. $\times 1000$

Fig. 7. Unequal divisions of blastomeres in Ascaris stam egg incubated with Stachybatrys chartarum. $\times 1000$

Fig. 8. Blastula and non-divided blastomere in Ascaris sawm ege ineubated with Stachybotrys chartarum. $\times 1000$

Fig. 9, Deformation of gastrule in Ascarts sutm egg incubated with Penicillium frequentans and Stachyborrys charianum. $\times 1000$

Fig. 10. Deformed larva in Ascaris suum egg incubated with Pentedlium fropquentans. $\times 1000$ 
In comparison with control, also significant delay and elongation of the gastrulation process was observed in the experimental cultures. This embryonic stage was observed in control eggs from day 11 to day 16 of the cultivation. The highest percentage of eggs in gastrula stage (ca 60\%) were stated on day 14 of the experiment. In eggs incubated with $\boldsymbol{P}$. frequentan.s, first gastrulae were observed as late as on day 28 and their maximum number (ca $40 \%$ ) were stated as late as on day 36 , that is, 22 days later as compared with control.

Significantly earlier, that is on day 21, maximal number of gastrulae (ca $40 \%$ ) were stated in the culture with $S$. chartarum, and somewhat later in the culture with both species of the fungi. On 26th day of incubation with $P$. frequentans and $S$. chartarum, $70 \%$ of eggs attained the stage of gastrula.

Blastula and gastrula deformations were observed in all experimental cultures (Fig. 8). The above changes appeared however, more often in eggs from cultures with $P$. frequentans. In many eggs, blastula or gastrula were accompanied by blastomeres arrested in development (Fig. 9)

In experimental cultures, as compared with control, the larval appearance was delayed 19 days in eggs incubated with $P$. frequentans, 13 days in eggs incubated with $S$. chartarum, and 17 days in cggs incubated with both fungi. In control, the highest percentage of larvae was observed on 11 and it amounted to $70 \%$, whereas not more than $25 \%$ of larvae were observed on day 40 and their number diminished in the following days down to $8 \%$ in the experimental culture I.

In cultures II and III, the development inhibition did not affect significantly the number of larvae, because, similarly with the control, the highest percentage of $L_{1}$ larvae amounted to $70 \%$, and until day $50-90 \%$ of eggs contain of $\mathbf{L}_{2}$ larvae.

In all experimental cultures, disorders in the development of larvae were stated. Most of larvae in the culture with P. frequentans and about $5 \%$ of them in the remaining experimental cultures had deformations in their structures. Deformed larvae were most often short and with irregular thickness (Fig. 10). Also partial development of gastrula to the partial larva was observed. All the larvae with irregular constitution were always motionless. In control, up to the end of the experiment, ca $90 \%$ of larvae were moving, and in all the experimental cultures, only single larvae showed the signs of viability on day $\mathbf{5 2}$ of experiment. All larvac, also those without visible morphological disturbances, were dead on day 72 of experiment.

No penetration of mycelium into eggs was observed throughout entire embryogenesis. No signs of destruction of egg shells were observed, either. Only in the eggs incubatcd with $P$. frequentans, various rates of degradation of dead larvae and destruction of egg shells were observed, starting on day 40 of culture. 


\section{DISCUSSION}

Results of the present study indicate on inhibitory effect, of mycelia of Penicilium frequentans and Stachybotrys chartarum, on the embryonic development of Ascaris suum the influcnce of $P$. frequentans being definitcly stronger. The above statement was justified by the fact that most of eggs incubated with $P$. frequentans remained at the stage of zygote for the longest period (up to the 25 th day). Also stages of morula and blastula persisted the longest time in most of eggs in the culture with the above fungus, that is up to day 29 , and the amount of eggs in the final cleavage stage was lower by 30 percentage points in comparison with control, and by 20 percentage points in comparison with the remaining experimental cultures. The slowest development pace of gastrula and $L_{1}$ larva was observed also in the culture with $P$. frequentans. The highest number of eggs with $\mathrm{L}_{1}$ larvac amounted to as little as $25 \%$. By the end of the experiment that is on day 52 only ca $5 \%$ of larvae showed the signs of viability.

L y s e k (1982) determined three stages of ovicidal effct of saprotrophic fungi to eggs of nematodes: 1 - without damage to the egg shells (ovistatic); 2 - with destruction of the egg shells only; 3 - with destruction of egg shells and penetration of mycelia of fungi into eggs.

Microscope observations carried out by the authors of the present study demonstrated only the ovostatic effect of both by $P$. frequentans and $S$. chartarum on the Ascaris cggs.

Significant morphological disorders in the developing embryos were stated, although degradation of egg-shells was not observed. The above fact indicates teratogenic properties of fungi secretions. The described disturbances in the developing eggs can be explained by penetration of metabolites secreted by the mycclia and showing properties of mycotoxins. As demonstrated by A r 1 h u I and S a n b o r n (1969), B a r r e t t (1976), as well as by C I a r k and P e r r y (1980) the nematode egg shells were the most resistant biological structures, permeable only to respiratory gases, water, and soluble lipids. The lipid layer (W h a r t o $\mathrm{n} 1980$ ) plays the most important role in protecting the embryo. It is possible that the secretions of the studicd fungi species have an aflinity to lipids and therefore they can penetrate through cgg shell. The observed vacuolisation of the zygote can be a result of accumulation of fungi secretions, and in turn, the vacuolisation can push the yolk to one of the poles, or to the equatorial plane. Certainly, an abnormal yolk distribution can have a decisive effect on the further blastomere divisions. As it is commonly known, the way of cleavage depends on the quantity and distribution of yolk in the egg. Yolk is distributed regularly in normal cggs of Ascaris. Certainly, translocation of yolk as a result of vacuolisation influences seriously the abnormalities in development, as early as during the first zygote division. In a number of eggs studied, already the first blastomeres differed significantly in size, and small ones contained no yolk at all, or they contained only very small quantities of yolk. 
Probably, blastomeres without yolk did not undergo further divisions bccause single, non-divided blastomeres were observed along deformed blastulae and gastrulac.

Parallel study on the activity of oxidative enzymes carried out by $\mathrm{K} 010 \mathrm{dz}$ i e j cz y k et al. (2001) showed that a delay in the development of eggs incubated with fungi could be caused by weakening of the respiratory processes which fact could suggest that mycotoxins were inhibitors of respiratory metabolism enzymes.

Enhanced toxic properties of $P$. frequentans as compared with toxic properties of $S$. chartarum were conlirmed also by the low rate of eggs, $(25 \%)$, that reached the $\mathrm{L}_{1}$ larva stage exposed to mycelium of $\boldsymbol{P}$. frequentans. Larvae of the next stage died out in the final period of the experiment, only $5 \%$ of larvae showed the symptoms of viability. In the culture with $S$. chartarum, as many as $90 \%$ of the larvae were viable in the same final stage of experiment.

The carried out experiment showed that both fungi species caused necrosis of all larvac in ca 70th day of incubation. All larvae were found to be dead on the above day, whereas most of larvae in control eggs, (95\%), were still viable. Lethal effect of the fungi on larvae could be connected with the enhanced penetrability of egg shell before hatching. A number of studies proved that the permeability of egg shell before hatching was caused by decomposition of diol ascarosides and acetylated aglycone that composed $70 \%$ of total ascarosides present in the layers of Ascaris egg shell ( $\mathrm{J} \mathrm{e} z \mathrm{y} \mathrm{k}$ and $\mathrm{F}$ a i r b a i $\mathrm{r}$ n 1967; T a r r and F a i r b a r n 1973; T a r r and S c h n o e s 1973). The mechanism of the above process was not clear. However, effect of chitinase was observed in the disolving of solution of the chitinous shell. Maximum chitinase activity occured in 20-day-old eggs (W a rd and Fair bairn 1972). Considering the delay in egg development in experimental cultures, also the activity of chitinase could be increased in the observed eggs. As observations described in the present paper show, damages of egg shells were observed only in eggs with dead embryos, it could be assumed that the damages resulted from the embryo necrosis and not from the ovicidal effect of mycelium.

The stated weakening of the toxic effect of $P$. frequentans in the presence of $S$. chartarum indicatc vaviability of properties of their metabolites. The results of the present study one consistent with the observations of $\mathrm{K} u \mathrm{n}$ e $\mathrm{It}$ and L y s e k (1987), Kunert et al. (1987), and K unert (1992). The above authors revealed the inter-specific and even intra-specilic vaviability of ovicidal properties of saprophytic fungi.

It should be assumed that studies on toxic propertics of fungi and their secretions should be carried out in a complex way, as properties of fungi can change depending on the complicated interrelations in the soil biocenosis. 


\section{REFERENCES}

A r t h u r E. J., S a n b o r n R. L. 1969. Osmotic and ionic regulation in nematodes. In: M. Flo r k i n, B. T. S c h e e r (eds). Chemical Zoology. 3. London, New York: Aced. Press.

B a r ret t J. 1976. Studies on the induction of permeability in Ascaris tumbricoides azgs Parasitology 73: $108-121$.

CIa r k e A. J Perry R. N. 1980. Egg-shell permeability and hatching of Ascaris suarn. Parasitology 80: $447-456$.

$\mathrm{Grzyb} Z \mathrm{~S}_{n}, \mathrm{Szydlows} \mathrm{ka} T, 1964$. Direct and indirect effect antibiotic on the development of Ascaris eggs cultured together with Escherichia coli and Provews mirabilits. Acta Prasitol. Pol. 8: $77-84$.

J a r nicke-Stanios H., Wawrzkiewicz K. 1974. Driałanie grzybów rodraju Fusarium na rozwój jaj Astaris suen. Wiad. Parazytol. 20: 829-837.

J e z y \& P.F, F a i z b a i r n D. 1967. Ascarosides and ascaroside esters is Ascaris lumbricoides (Nemareda). Comp. Biochern. Physiol. 23: 691 - 705.

Kolodziejezyk L, Kuźna-Grygiel W, Janowicz. M. Mazurkicw i c z - Z a p a 10 w i c z K. 2001. Eflect of fungi Penicillum frequentans and Stachyboirys charianim on respiratory metabolism on developing eggs of Ascaris sum (Nematoda). Acta Mycol. 36 (1): $159-168$.

K r as a o o s LN. 1978. Mnogoletnaja wyzywaemost jajc ascarid Ascaris lumbricoides L. w pocve Samarkanda. Med. Parazitol. Parazitam. Bol 28: 400-405.

K u a e r t J, 1992. On the mechanism of penetration of ovicidal fungi through egg-sbells of parasitic nematodes. Decomposition of chitinous and ascaroside layers. Fol. Parasitol. 39: $61-66$.

$\mathrm{K}$ u a e r t J, L y s c k H. 1987. Lipolytic activity of ovicidal soil fungi. Biologia 42: 285-293.

$\mathrm{K}$ u a e r t J, Z e m e k J, A u gust i J., K u n i a k C. 1987. Proteolitic activity of ovicidal soil fungi. Biologia $42: 695-705$.

L y s e k H. 1963. Effect of certain soil organismus on the eggs of parasitic roundworm. Nature 31: 925.

L y s e k H. 1967. Biological liquidation of ascarid eggs in spring pasture soil. Acta Parasitol. Pol. 15: $263-267$.

L y $s$ e k H. 1979. To the problem of possible biological control of geohelminthoses. Helmintologia 16: $107-113$.

L y s e K H. 1982. The problem of humans geohelminthoses and the prospects for their biological control. Acta Unir. Palack. Olom. 103: $315-328$.

Mazurkiewicz-Zapalowicz K, JanowiczK, Kuzna-Grygiel W. 1999. Influence of excrections of chosen Penicillitm species on the population Globadera rostochientis. Acta Mycol. 34 (2): $289-297$.

$\mathrm{M} \mathrm{i} 2 \mathrm{~g} \mathrm{a} \mathrm{j} \mathrm{s} \mathrm{k} \mathrm{H.} \mathrm{1993.} \mathrm{The} \mathrm{distribution} \mathrm{and} \mathrm{survival} \mathrm{of} \mathrm{eggs} \mathrm{of} \mathrm{Ascaris} \mathrm{swem} \mathrm{in} \mathrm{six} \mathrm{different}$ natural soil profiles. Acta Parasitol. 38: 170-174.

M i z g a j s k a H. 1994. Wpływ czynników biotycznych na jaja Ascarís spp. Wiad. Parazytol. 40: $299-303$.

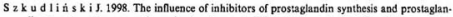
dins on Ascaris sutum embryonic development. Wiad. Parazytol. 44:663-670.

T a r r G.E., F a i r b a i r n D. 1973. Ascarosides of the ovaries and eggs of Ascaris lumbricoides (Nematoda). Lipids 8: 7-16.

T a r r G. E., S c h D o e 8 H. K. 1973. Structures of ascaroside aglyeone. Arch. Biochem. Biophys. 158: $288-296$

W a $\mathrm{r}$ d K. A, F a i r b a i r a D. 1972. Chitinase in developiag eggs of Ascaris sumn (Nemetoda). J. Parasitol. 58: 546-549.

Wh a rt on D. 1980 . Nematode egg-shells. Parasitology 81: 447-463. 


\title{
Wplyw wybranych saprotroficznych grzybów glebowych na rozwój embrionalny Ascaris sum
}

\author{
Streszczenic
}

Badano oddzialywanie grzybow Penicillium frequenians i Stachyborrys chartarum aa rozwój zarodkowy Ascaris suum. W jajach inkubowanych z grzybami wykazano znaczne opozaienie inicjacji podziału zygoty i spowolnieaie rozwoju poszezegolnych stadiow embriogenezy. Ponadto obserwowano wakuolizację zygoty i zaburzenia w rozmieszczeniu substancji zółkkowej, nicsynchronicone i nierównomierne podziały blastomerów, deformacje stedium blastuli, gastruli i larwy, a zmiany te wyrażaiej manifestowaly sị w jajach inkubowanych z $P$. frequentans. W hodowli $z P$. frequentans stwierdzono znacznie mniejszy odsetek larw i wczesniejsze ich obumieranie. Badania wykazały, że toksycrne własciwości metabolitów $P$. frequentens sq znacznie slabsze w obecności grabai drugiego badanego gatunku $S$. chartarum. 